\section{COMPARATIVE ENDOCRINOLOGY}

Animal Hormones

A Comparative Survey. By Dr. Penelope M. Jenkin. Part 1: Kinetic and Metabolic Hormones. (International Series of Monographs on Pure and Applied Biology. Division: Zoology, Vol. 6.) Pp. $x v+310$. (London and New York: Pergamon Press, 1962.) 45s. net.

$\mathrm{D}$ URING recent years the study of comparative endocrinology has attracted an increasingly large number of workers, and the data that they have gathered begin to form an adequate foundation for generalizations about groups of hormones and their action. In her book, Dr. Jenkin abandons the traditional approach to endocrinology, namely, that of listing endocrine organs and their hormones, in favour of a more physiological approach. She classifies hormones according to their action and thus deals with endocrine activity under the three main headings of kinetic, metabolic and morphogenetic hormones. Her work is planned in two volumes, and this, the first, deals with kinetic and metabolic hormones. It is a pity that it was not possible to publish both volumes simultaneously since the actions of metabolic and morphogenetic hormones are closely integrated in growth and development.

The history of the endocrinology of vertebrates and that of invertebrates differ in one very important respect. Vertebrate endocrinology was based on morphology; the structure of the endocrine organs was known before their function was established. Endocrine function in the invertebrates, however, was established experimentally before the sources of the hormones had been determ. ined precisely. Many of the early experiments, especially on invertebrates, involved reciprocal injections of crude extracts between animals of different species and even phyla. Dr. Jenkin very wisely avoids these on the grounds that they are apt to lead to unsound physiological deductions. She has instead chosen separate instances of endocrine control in members of different phyla and placed these side by side to show that unrelated animals may have hormones with similar actions.

Since it is the expressed intention of the book to point to similarities in hormones by classifying them according to the functions which they control, it is therefore pertinent to enquire whether the comparative and physiological approach does, in fact, in our present state of knowledge, tend to reveal similarities. Certainly there are broad resemblances in the effect of hormones, yet it is clear that many hormones which have somewhat similar effects may have little else in common. For example, the 'kinetic' hormones, which are defined here as those which act on effectors in ways which often resemble the effects of nerve stimulation, seem to include small and large molecules of very different chemical structure; they are derived from modified nervous tissue, nonnervous ectoderm or endoderm; moreover, sorme appear to be excitatory and some inhibitory in their effects on their target organs.

In the hands of a skilful and experienced teacher like Dr. Jenkin, or as an adjunct to a more traditional book on endoerinology, this book could prove valuable and stimulating. The text is clear and there are useful tables and some very helpful illustrations. It is not surprising, in view of the wide field of knowledge encompassed, that there are some misleading statements. For example, the text suggests that vasopressin and antidiuretic hormone are two distinct entities, and it is a pity that the pituitary of the rabbit has been chosen as an example to illustrate the blood supply to this organ as the condition in this species is not typical of mammals as a whole. There is also, perhaps, a certain unevenness of treatment, with too great an emphasis on invertebrate endocrine control, and the attempt to present a complete comparative account has led to a somewhat fragmentary presentation which makes the book more suitable as a reference manual than as a text-book. Dr. Jenkin has, however, performe 1 a very valuable service by presenting to endocrinologists a comparative survey which contains a great deal of material which is not available in other books on endocrinology. The comparative physiological approach is thought-provoking and a necessary preliminary to a consideration of whether, at the biochemical level, there may be certain fundamental features of endocrine control.

Francis Knowles

\section{PROBLEMS IN CANCER RESEARCH}

\section{Progress in Experimental Tumor Research}

Vol. 3. Edited by F. Homburger. Pp. xvi+456. (Basel and New York : S. Karger, 1963.) 81 Swiss Francs.

HE third volume of this series is, if anything, of a higher standard and of greater interest than its predecessors. It is dedicated to the late and universally respected Francisco Duran-Reynals, and contains an excellont review on the combined effects of chemical agents and viruses by his widow and co-worker. Experimental work in this interesting field from 1923 until the present day is critically discussed and the chapter as a whole provides an excellent background for the one which follows by Kotin and Wiseley. The latter provide a well-illustrated account of their experimental induction of squamous cell carcinomas in the lungs of mice by inhalation-exposure to 3 strains of influenza virus and aerosols of hydrocarbons. Stansly discusses the similarities and differences of various virus-induced leukæmias and related diseases of mice. Among the points he emphasizes at the end of his account are: (1) that some of these agents are antigenic, and others not; (2) that a given preparation of 'an agent' may induce histologically different lesions, and that it is not known whether this is due to multiplicity of agents or pluripotentiality of a single agent; (3) that electron microscope studies show these agents to be of similar structure whereas biochemical and biological studies indicate marked differences.

Dmochowski, as is typical of him, provides a long and competent chapter on tumour viruses with particular reference to the electron microscopic view of virus-host relationship. An important conclusion of this contributor is that: "There is a striking similarity between oncogenic and infectious viruses in respect of their structure and the mode and sites of their replication". Bernhard covers some of the same ground in his chapter, "Some Problems of Fine Structure in Tumour Cells". However, the main emphasis here is on the variety of cellular alterations observed during the development of oncogenic agents. The author writes: "Not only are the structure and size of these agents quite different, but also their location in the cells and the primary or secondary losions which thoy induce. ... It is hardly conceivable that the lesions which are visible in the electron microscope are, per se, responsible for the oncogenic process. . . " Bernhard looks to such methods as marking viral nucleic acids with radioactivo tracers and combining autoradiography with electron microscopy to provide further advances in this field.

The strength of radiotherapy as compared with chemotherapy as a weapon in cancer treatment depends on the elaboration of techniques for delivering its lethal effects at, and only at, the required points. Its weakness is its failure to discriminate between normal and cancerous tissues. In his chapter on the "Experimental Radiotherapy of Malignant Tissues", Sikov devotes only a short space to the efforts made towards overcoming this weak ness. The transplantable rat hepatoma 5123, of Morris, has been described by Van Potter and others as an example 